\title{
TWO-INDUCTOR BOOST CONVERTER START-UP AND STEADY-STATE OPERATION
}

\author{
Luis A. Flores-Oropeza, Alejandro Román-Loera, Jorge E. Macías-Díaz ${ }^{1}$, Felipe de J. Rizo-Díaz \\ Departamento de Sistemas Electrónicos and ${ }^{1}$ Departamento de Matemáticas y Física, \\ Universidad Autónoma de Aguascalientes, Aguascalientes, Ags., Mexico \\ 1flores@correo.uaa.mx; aroman@correo.uaa.mx; jemacias@correo.uaa.mx; frizo@correo.uaa.mx
}

\begin{abstract}
In this work, an isolated DC/DC twoinductor boost converter is proposed. The topology is able to start up and operate in steady-state at any output level within $0 \mathrm{~V}$ to $400 \mathrm{~V}$. The current and voltage characteristics make this topology suitable for applications where the relationship between input current and output voltage is too long, such as applications in hybrid electric vehicles (HEVs). In order for its operation to be possible at any output level, two auxiliary windings were added. These auxiliary windings were included to ensure that the startup current does not rise to a higher level, as opposed to other isolated boost converters where the start-up current level is high. The design of the converter and a detailed analysis are given; an experimental $200 \mathrm{~W}$ prototype is presented to validate the converter operation and its design.
\end{abstract}

Keywords - Automatic transition, Boost-Flyback effect, Normal mode, Start-up mode.

\section{INTRODUCTION}

The boost converter with two inductors and isolation is shown in Figure 1. The use of this topology is not popular; however, some authors have proposed it to be used in some applications. Reference [1] presents a study that performs an integration of the magnetic component to this topology, for high input current and low output voltage; in [2] and [3], the addition of an auxiliary transformer is provided, this transformer connects the coils currents and, through this connection, the output voltage is improved to manage a wide range of loads. With the addition of this auxiliary transformer, the topology is able to reach a high relation between the input and the output voltages, making of this topology an ideal one for applications in which there is a great difference between these voltages. In [4], the author proposes the converter as an attractive alternative to work in those situations where this relation of input and output voltages is required. Reference [5] is a comparative study between the Push-Pull fed current converter and the Two-Inductor Boost converter with a PushPull output, calling it Dual Inductor Converter (DIC). In [6], the addition of a resonant circuit to the topology to improve its performance with high currents and low input voltage is presented. Finally, [7] compares the topology shown in Figure 1 against a converter that contains a center tap transformer with a low input voltage and high current.

Manuscript received 25/03/2009. Revised on 30/03/2010 and 06/05/2010 Accepted for publication in 18/05/2010 by recommendation of the Editor Fernando L. M. Antunes.
However, in all the works previously mentioned, there are no designs that use duty cycles lower than $50 \%$ in steady-state form, a task which is performed by the topology presented in this paper. In [8] and [9], a full bridge fed current converter is presented; the author proposes the addition of an aid winding in order to start-up the converter and mentioned that this kind of start-up can be applied to the other isolated boost converters. In this paper, an analysis of the two-inductor boost converter with two aid windings is made in order to propose the operation of this topology not only to start-up. Steady-state operation with duty cycles lower than 50\% can be obtained if the designs of the transformers and inductors are adequately.

\section{PROPOSED CONVERTER}

In Figure 2, the isolated two-inductor boost converter that operates as a boost converter is presented. This topology is integrated by two switches MOSFETs M5 and M6, a full bridge rectifier (D1-D4), two diodes (DF1 and DF2), a transformer TR, two inductors $\mathbf{L} 1$ and $\mathbf{L 2}$, two auxiliary windings - each one placed in one of the inductors - that conform a Flyback transformers (TF1 and TF2).

In order to analyze the operation of this converter in steadystate, it is recommended to do it in two parts: one, when the duty cycle is between $0 \%$ and $50 \%$ (Start-up), and the other when the duty cycle is between 50\% and 100\% (Normal). In spite of being called 'start-up', the converter can also operate in steady-state in this mode, with the aid of the auxiliary windings.

It is important to mention that the proposed converter operates exactly in normal mode, as in Figure 1, when it is not using the auxiliary windings in this operation mode. Auxiliary windings operate only when the duty cycle is lower than $50 \%$.

Characteristics like high current capability, galvanic isolation and small component count, make from this topology a good candidate to be utilized in applications where a great relation between input and output voltage are necessary. Operation modes of this DC/DC converter can be seen in Figure 3. The equivalent circuit that is operating in each area is also shown.

\section{A. Operation modes}

MOSFETs M5 and M6 control the output voltage regulating the duty cycle $d$. In order to analyze the operation principle of this converter, it is necessary to split it in two parts: One considering the duty cycle between $50 \%$ and $100 \%$ (called Normal), and other one considering the duty cycle between $0 \%$ and $50 \%$ (called Start-up).

\section{1) Normal operation}

When the duty cycle is between $50 \%$ and $100 \%$, then the 


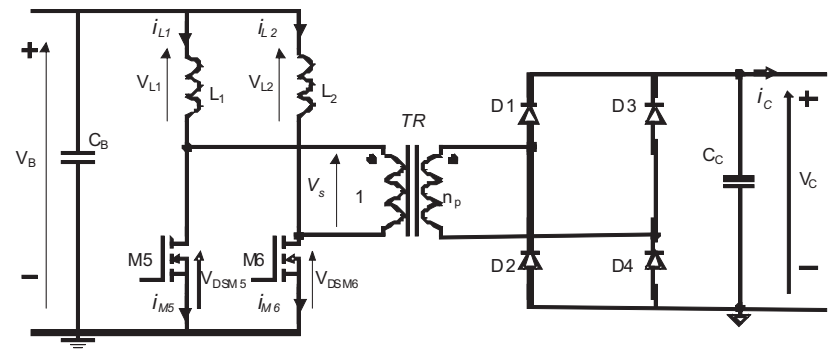

Fig. 1. Isolated two-inductor boost converter.

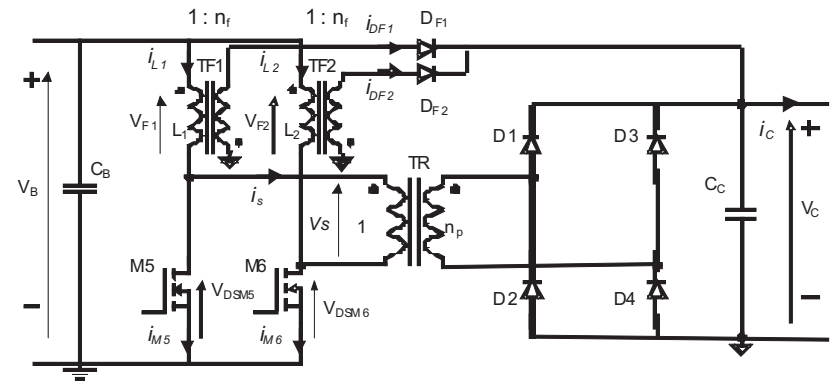

Fig. 2. Proposed converter with two aid windings.

converter works as a boost converter. Figure 4 shows the typical waveforms in this operation mode. In continuous conduction mode (CCM) the equation that defines the gain of the converter, based on duty cycle $d$ and turns ration $n_{p}$, is:

$$
k_{N}=\frac{V_{C}}{V_{B}}=n_{p} \frac{1}{1-d}, \quad 0.5 \leq d \leq 1 .
$$

\section{2) Start-up operation}

The conventional converter topology (Fig. 1) cannot operate by itself with duty cycles lower than $50 \%$. The reason is that the energy that is stored in the inductors $\mathbf{L} \mathbf{1}$ and $\mathbf{L} \mathbf{2}$ for this duty cycle cannot be transferred to the output after being turned off. It is necessary to look for an additional path for the current in order to avoid a high voltage that can damage the MOSFETs. Two additional windings with two diodes (DF1, DF2) are placed to transfer the energy to the output. Figure 2 , shows the additional windings in the inductors and diodes.

Additional windings and diodes make of this topology an alternative to operate in steady-state with duty cycles lower

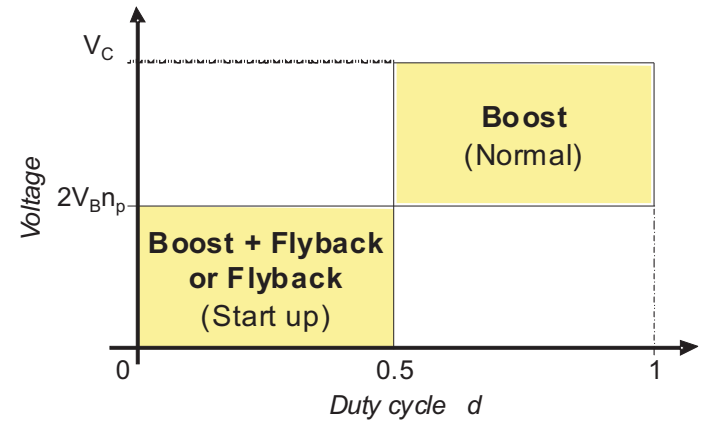

Fig. 3. Equivalent circuit in each operation mode in the proposed converter. than $50 \%$. With these additional windings and diodes, two patterns can be used to start up the converter from $0 \mathrm{~V}$ to any output voltage called Start-up I and Start-up II. These two starts-up operation modes take advantage of the inductors that have auxiliary windings and they use them like transformers (TF1 and TF2). Start-up I uses these two transformers to transfer the energy to the output as two Flyback transformers, whereas Start-up II uses them in an alternate way: Main transformer TR as boost converter, and transformers TF1 and TF2 as Flyback transformers.

- Start-up I (Flyback) In this start-up method, M5 and M6 are switched on at the same time. In this way, the energy is stored in each transformer (TF1 and TF2) and later it is transferred to the output through DF1 and DF2. This operation mode is equivalent to place two Flyback converters in parallel. In this method, once that the $50 \%$ in duty cycle is reached, the sequence of control in the MOSFETs changes to normal operation and it continues working as a boost converter through the main transformer (TR). Control signals change from being in phase to being shifted $180^{\circ}$. In order to do this change in the control signals, it is necessary to use a circuit that detects when the $50 \%$ in duty cycle has been reached and, at the same time, changes the operation sequence of the control pulses. In CCM, the equation that defines the gain of the converter applying volts balance in one flyback transformer (TF1 or TF2) of the converter in one switching period is:

$$
k_{S 1}=\frac{V_{C}}{V_{B}}=n_{f} \frac{d}{1-d}, \quad 0 \leq d \leq 1,
$$

where $n_{f}$ is the turn-relation in auxiliary windings.

- Start-up II (Boost+Flyback) This start-up method is a combination of the Boost converter and a Flyback converter. Start-up II occurs by default when the auxiliary windings are placed in the inductors of the converter, as long as the duty cycle in the control signals of M5 and M6 vary from $0 \%$ to $50 \%$ and are $180^{\circ}$ delayed. With the addition of these auxiliary windings in the inductors, it is possible for the converter to work in steady-state for any duty cycle lower than $50 \%$. With this method, the converter changes automatically to normal operation as a boost converter when duty cycle reaches $50 \%$, without the need of a circuit to make this transition like in Startup I. In addition, with this new structure, the output voltage can be controlled for duty cycles lower than $50 \%$. Figure 5 shows the key waveforms for this method. This operation mode is quite different from the classical solutions. If the converter operates in CCM, making a volts balance in any of the inductors (TF1 or TF2) of the converter in one switching period, the equation that defines the gain of the converter based on duty cycle $d$ and turns-relations $n_{p}$ and $n_{f}$ is:

$$
k_{S 2}=\frac{V_{C}}{V_{B}}=\frac{2 d}{\frac{1-2 d}{n_{f}}+\frac{d}{n_{p}}}, \quad 0 \leq d \leq 0.5 .
$$




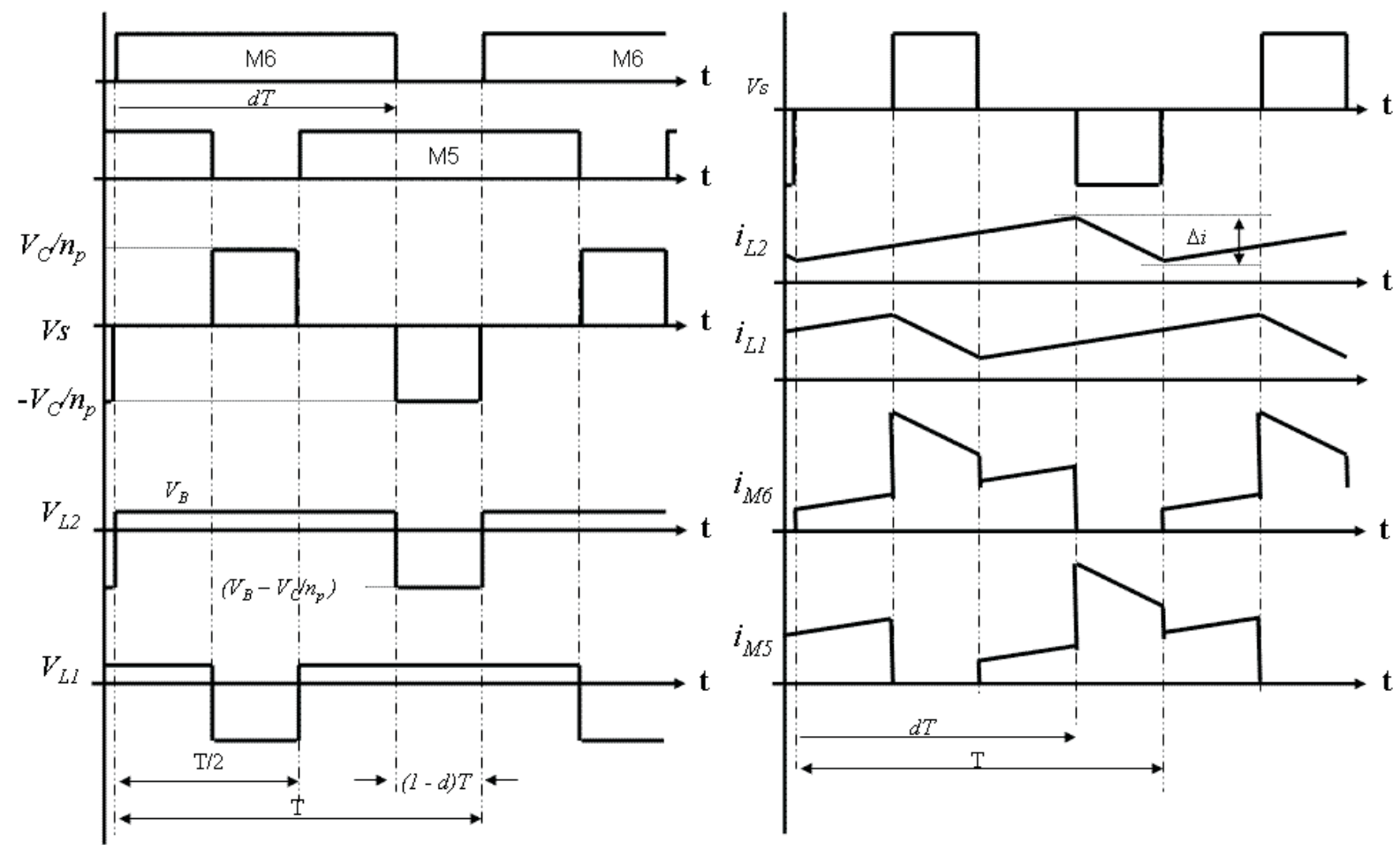

Fig. 4. Waveforms in Normal operation.
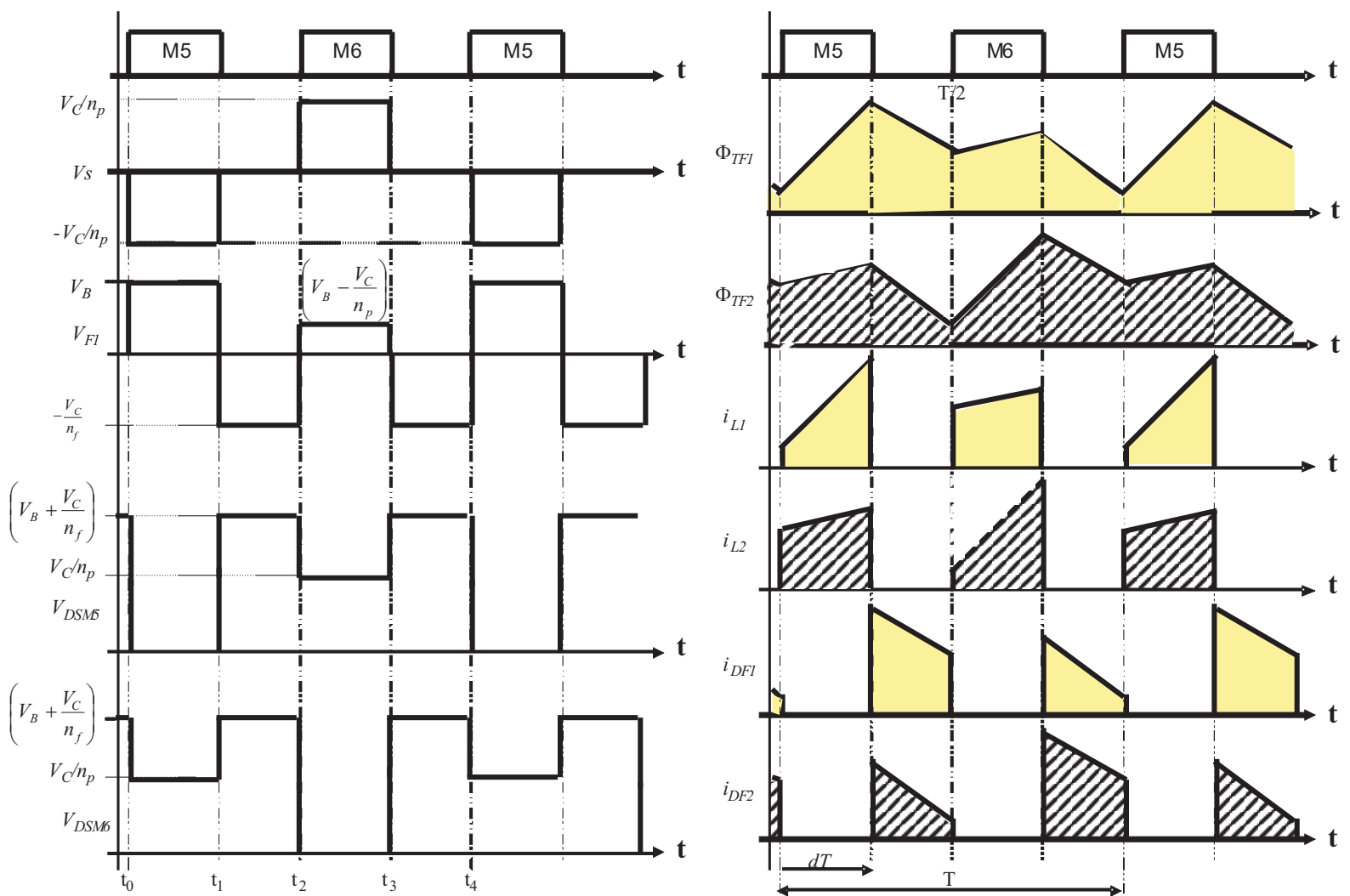

Fig. 5. Waveforms in Start-up II. 


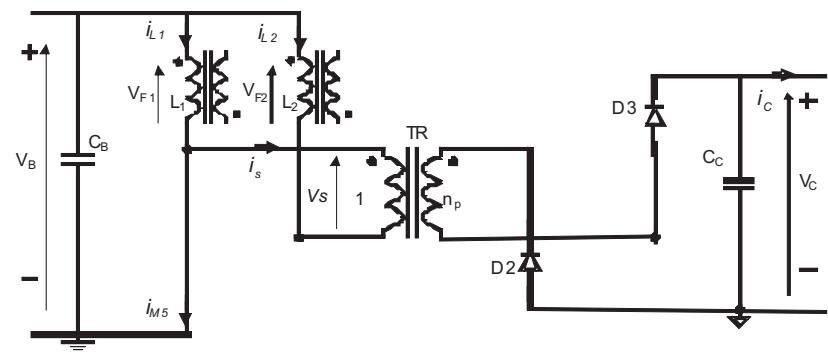

Fig. 6. Equivalent circuit for $\mathbf{t}_{\mathbf{0}}-\mathbf{t}_{\mathbf{1}}$.

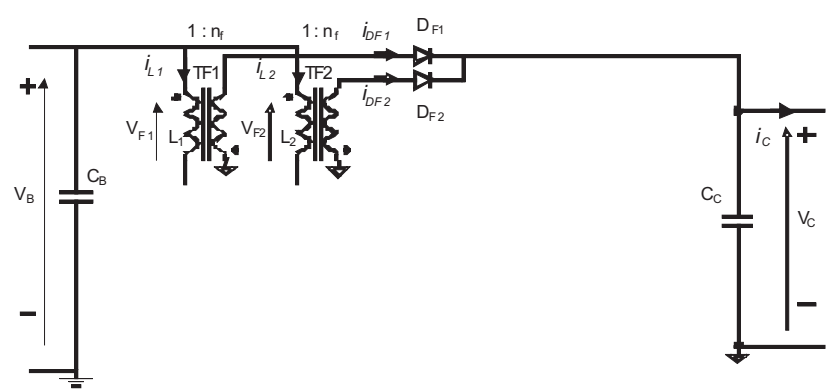

Fig. 7. Equivalent circuit for $\mathbf{t}_{\mathbf{1}}-\mathbf{t}_{\mathbf{2}}$.

Four basic operations modes in a period of commutation can be identified; the equivalent circuits in each mode and explication are defined next:

- $\mathbf{t}_{\mathbf{0}}-\mathbf{t}_{1}$ In this interval, M6 is off and M5 is on, causing the current $i_{L 1}$ to increase linearly with the input voltage $V_{B}$ and storing energy in the core of transformer TF1 as Flyback (see Figure 6). At the same time, energy that was previously stored in the core of TF2 is transferred to the output through the main transformer TR like a boost converter. This causes that $i_{L 2}$ circulate around the primary one of TR. Current $i_{L 1}$ and current $i_{L 2}$ add up since both circulate in MOSFET M5.

- $\mathbf{t}_{1}-\mathbf{t}_{2}$ In this interval, M6 is still off and M5 is off, causing the current $i_{L 1}$ to circulate through the secondary of TF1 and diode DF1, delivering energy to the output capacitor CC. At the same time, the current $i_{L 2}$ changes to circulate through the secondary of TF2 and diode DF2 to deliver energy to the output, too. In both cases the energy is transferred like a Flyback converter (see Figure 7 ). On the other hand the magnetizing current of

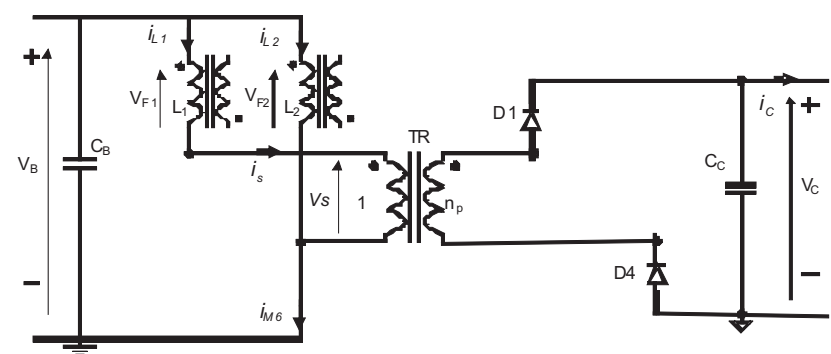

Fig. 8. Equivalent circuit for $\mathbf{t}_{\mathbf{2}}-\mathbf{t}_{\mathbf{3}}$.

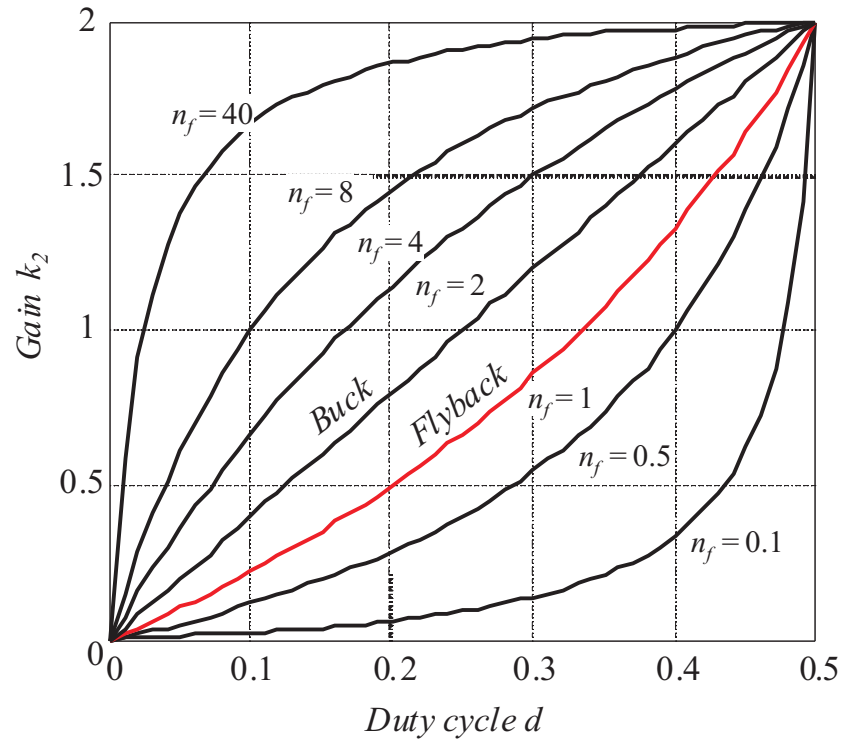

Fig. 9. Gain of the converter varying $n_{f}$ with $n_{p}=1$.

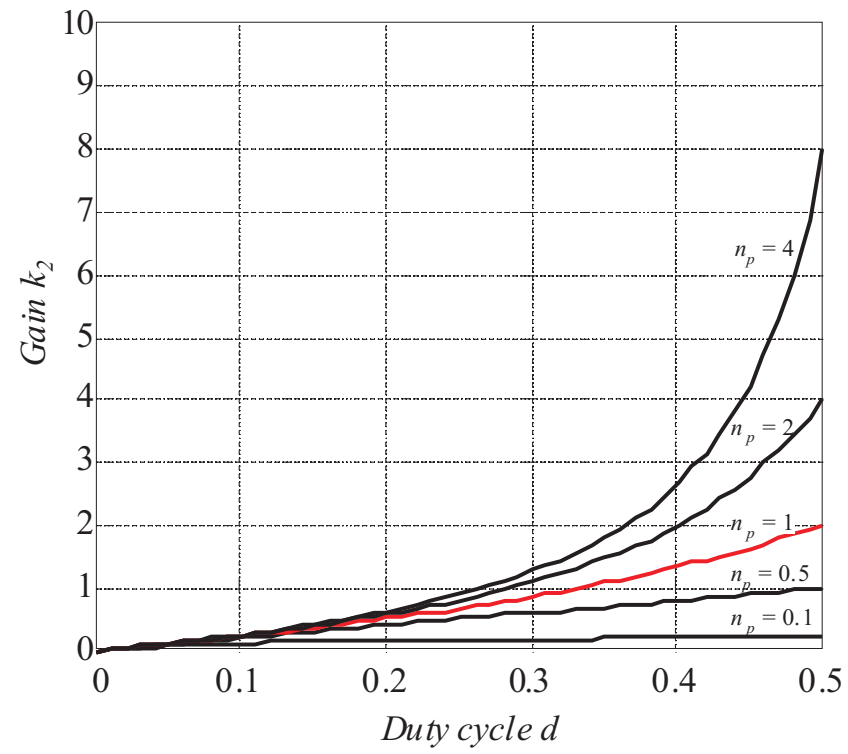

Fig. 10. Gain of the converter varying $n_{p}$ with $n_{f}=1$.

main transformer $\mathbf{T R}$ circulates through the diodes D1D4. This current does not appear in the circuits of Figure 7 due to the fact that it is meaningless when compared to the load currents of the converter, which are significant.

- $\mathbf{t}_{2}-\mathbf{t}_{\mathbf{3}}$ This interval is similar to the interval $t_{0}-t_{1}$ with different components, since M5 is still off and M6 on. In summary, in this interval, part of the energy is stored in TF2, and another part is transferred through TR thanks to the energy previously stored in TF1 (see Figure 8). The slope of the current $i_{L 1}$ in this interval can be positive, zero or negative. If the output voltage reflected in primary of $\mathbf{T R}$ is smaller, equal or greater than the input $V_{B}$, the slope is positive, zero or negative, respectively. In this case, in Figure 5 the output voltage reflected in the primary of $\mathbf{T R}$ must be lower than $V_{B}$ 
TABLE I

Voltage stresses in semiconductors

\begin{tabular}{ccc}
\hline Semiconductor & Start-up & Normal \\
\hline D1-D4 & $V_{C}$ & $V_{C}$ \\
\hline M5-M6 & $V_{B}+V_{C} / n_{f}$ & $V_{C} / n_{p}$ \\
\hline D $_{\text {F1-DF2 }}$ & $V_{C}+n_{f} V_{B}$ & $V_{C}+n_{f} V_{B}$ \\
\hline
\end{tabular}

since the slope of the current $i_{L 1}$ in this interval is positive.

- $\mathbf{t}_{\mathbf{3}}-\mathbf{t}_{\mathbf{4}}$ By symmetry in this interval occurs the same like in $t_{1}-t_{2}$. In summary, in this interval the energy transference becomes from main input to the output by effect of Flyback converter through TF2 and TF1 (see Figure 7). This is the last interval of analysis and the process is repeated here.

Two particular behaviors in (3) that define the gain of this operation mode like a Buck and a Flyback converter can be identified varying the turns-relations between $n_{p}$ and $n_{f}$.

If $n_{f}=2 n_{p}$, the obtained gain is like the one of a Buck:

$$
k_{S 2 B u c k}=\frac{V_{C}}{V_{B}}=4 n_{p} d, \quad 0 \leq d \leq 0.5 .
$$

In the other case, if $n_{f}=n_{p}$, the gain is like the one of a Flyback:

$$
k_{S 2 \text { Flyback }}=2 n_{p} \frac{1}{1-d}, \quad 0 \leq d \leq 0.5 .
$$

In Figure 9, observe that the gain achieves the same maximum value when the duty cycle achieves $50 \%$ for any value of $n_{f}$, and $n_{p}=1$; the gain is like that of a Buck and a Flyback for $n_{f}=1$ and $n_{f}=2$, respectively.

When $d=0.5$, a constant value is achieved in (4). For example, maintaining $n_{f}=1$ and varying $n_{p}$, yields a total converter gain equal to $2 n_{p}$ (see Figure 10).

\section{CONVERTER DESIGN}

In order to design the converter, it is important to know some design parameter, like stress voltages and effective currents in the components of the converter. The first things to determine are the turns-relations of the transformer $\mathbf{T R}$ and the auxiliary windings in the coils.

\section{A. Semiconductor voltage stresses}

Table I shows the voltage stresses in each semiconductor of the converter. It shows that M5 and M6 are the only stresses that may be penalized, in view that they may actually differ in their values in Normal and Start-up mode.

\section{B. Inductance calculation}

As the inductors are placed in the low voltage side of the converter, the minimum number of turns has to be assigned in order to reduce the resistance and minimize the path through which the high currents circulate. Clearly, (6) serves to calculate the value of the inductance of the inductors of the converter with a $100 \%$ from peak to peak, in order to ensure that the design will be made with the minimum turns in the
TABLE II

Prototype specifications

\begin{tabular}{lc}
\hline Battery voltage range $\left(V_{B}\right)$ & $10 \mathrm{~V} \approx 16 \mathrm{~V}$ \\
\hline Capacitor voltage $\left(V_{C}\right)$ & $0 \mathrm{~V} \approx 420 \mathrm{~V}$ \\
\hline Output power $\left(P_{o}\right)$ & $200 \mathrm{~W}$ \\
\hline Switching frequency $\left(f_{s}\right)$ & $100 \mathrm{kHz}$ \\
\hline
\end{tabular}

TABLE III

Magnetics and semiconductors

\begin{tabular}{cl}
\hline Element & Description \\
\hline D1-D4 & STP20NM60 \\
\hline M5-M6 & HUF75639P3 (3 in each branch) \\
\hline TR & E/42/21/15-3C85 (1:7) Prim = 6 turns (solid copper \\
& $0.75 \mathrm{~mm}), \mathrm{Sec}=42$ turns (7 parallel solid copper \\
& $0.75 \mathrm{~mm})$ \\
\hline TF1-TF2 & L=7.5 $\mu \mathrm{H}$ \\
& Kool Mu 77083A7, (1:7) Prim = 10 turns (3 parallel \\
& litz 400x0.07mm), Sec $=70$ turns (solid copper \\
& $0.75 \mathrm{~mm})$ \\
\hline
\end{tabular}

inductors. Here, $P_{0}$ represents the output power:

$$
L=\frac{2}{P_{0}}\left(V_{B}^{2}-\frac{n_{p} V_{B}^{3}}{V_{C}}\right) \frac{1}{f_{S}} .
$$

\section{Start-up selection}

When the converter has to work with more than $50 \%$ in duty cycle, the converter initializes with one start-up (Start-up 1 or 2); afterwards, it change to Normal operation mode when duty cycle exceeds $50 \%$. In order to do this correctly, some conditions have to be satisfied to select $n_{p}$ and $n_{f}$ in each startup.

\section{1) Start-up I + Normal mode}

When duty cycle in Start-up I reaches $50 \%$, then the gain in (2) has to be the same as the gain in (1). Setting both equations equal to each other and solving for $n_{f}$, we obtain:

$$
n_{f}=2 n_{p}
$$

This condition has to be satisfied to ensure that the output voltage in Start-up I be the same in Normal mode, when the duty cycle be $50 \%$.

2) Start-up II + Normal mode

When the duty cycle is $50 \%$, both Start-up II and Normal mode have the same value in their corresponding converter gains. Their values are equal to $2 n_{p}$, which means that in this start-up we can select any value for $n_{f}$ and the transition will be made without any variation in the output voltage. The only restriction is in the stress voltage in M5 and M6, as shown in Table I.

\section{EXPERIMENTAL RESULTS}

A prototype circuit with low output power was designed and tested in order to verify each operation mode, Normal $(d>50 \%)$ and Start-up $(d<50 \%)$. The specifications of the prototype are shown in the Table II. Start-up II was selected due to the fact that, making $n_{p}=n_{f}$, results in a Flyback start-up converter with a natural transition from Start-up to Normal mode. The converter was tested in two different output 


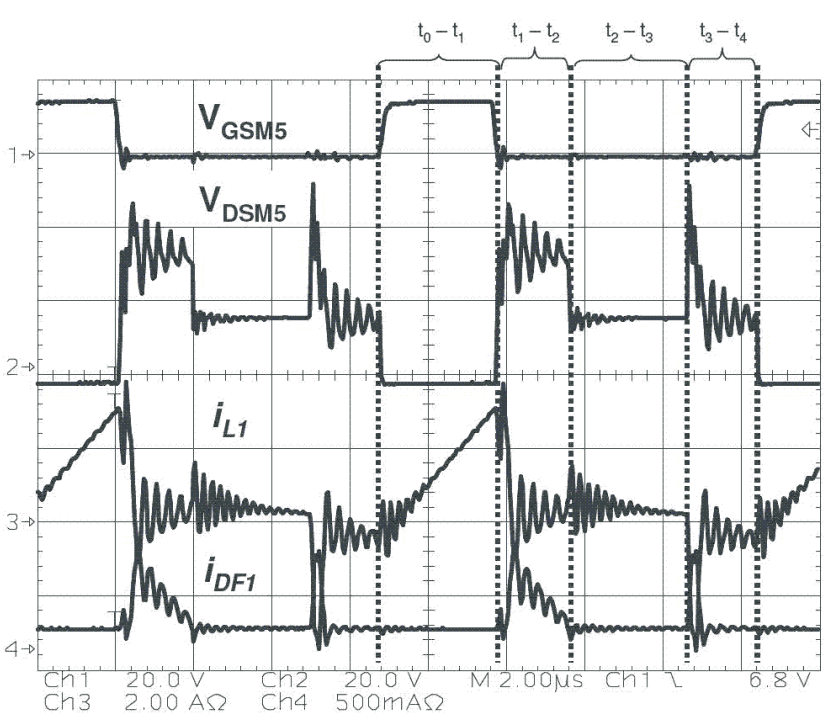

Fig. 11. Waveforms for $V_{C}=100 \mathrm{~V}$.

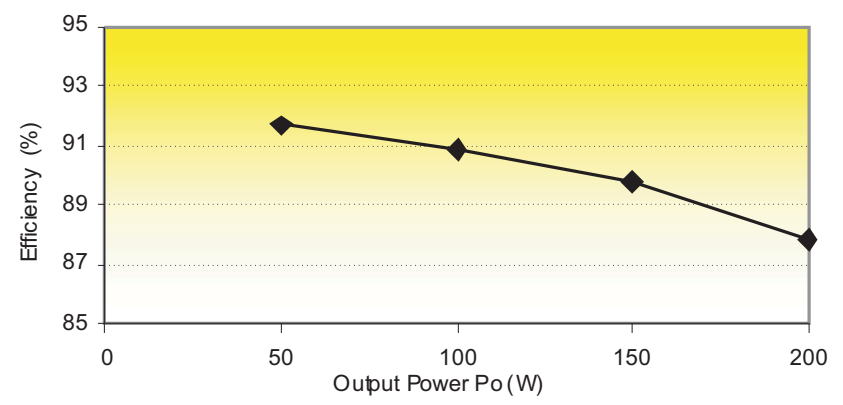

Fig. 12. Efficiency of the converter for $V_{B}=14 \mathrm{~V}$ and $V_{C}=100 \mathrm{~V}$.

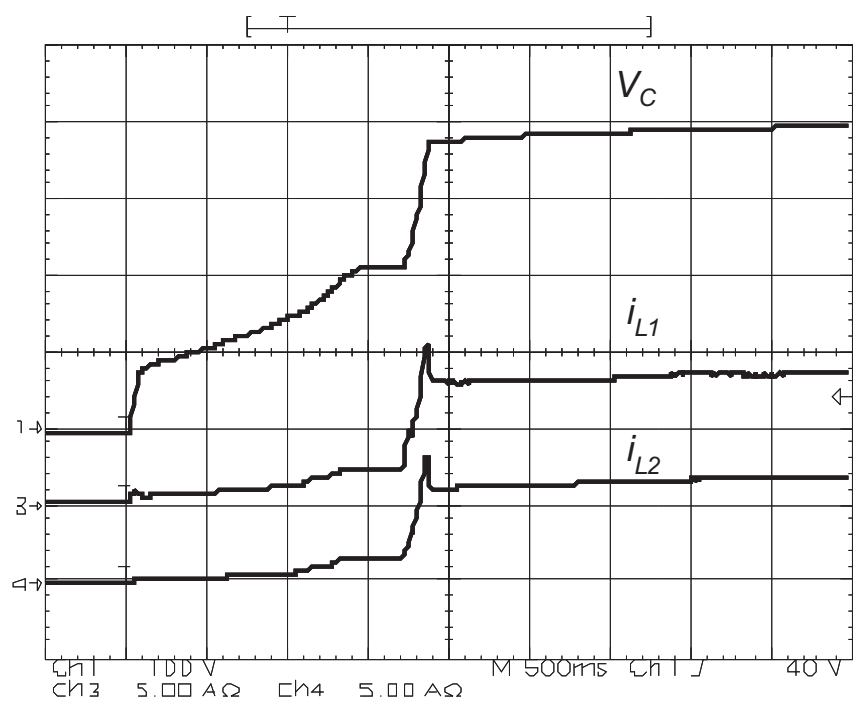

Fig. 13. Output voltage, $V_{c}(100 \mathrm{~V} / \mathrm{div}, 500 \mathrm{~ms} / \mathrm{div})$, current through L1, $i_{L 1}(5 \mathrm{~A} / \mathrm{div}, 500 \mathrm{~ms} / \mathrm{div})$, current through $\mathbf{L 2}, i_{L 2}(5 \mathrm{~A} / \mathrm{div}$, $500 \mathrm{~ms} / \mathrm{div})$.

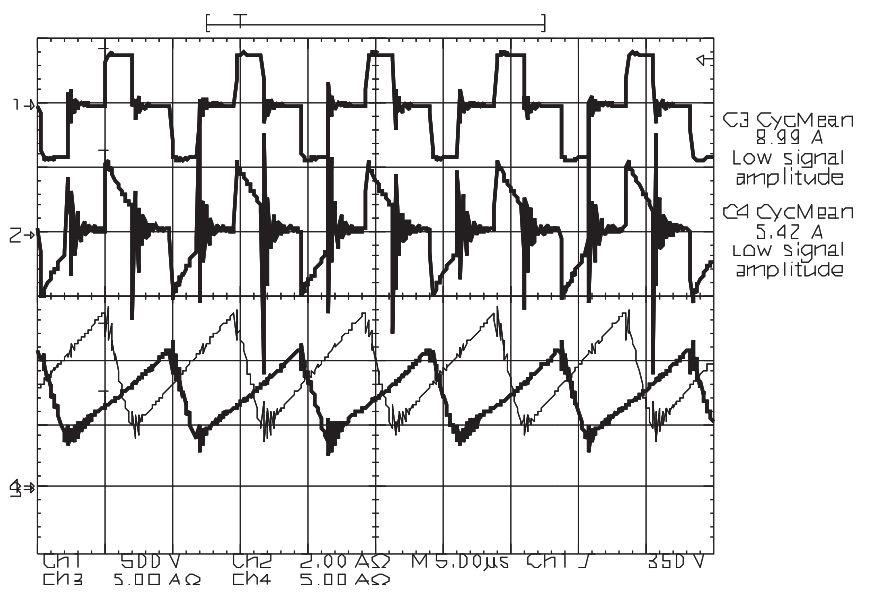

Fig. 14. Voltage of the secondary of transformer TR, $V_{p}(500 \mathrm{~V} /$ div, $5 \mu \mathrm{s} / \mathrm{div})$, current of the secondary of transformer $\mathbf{T R}, i_{p}(2 \mathrm{~A} / \mathrm{div}$, $5 \mu \mathrm{s} / \mathrm{div})$, current through $\mathbf{L} 1, i_{L 1}(5 \mathrm{~A} / \mathrm{div}, 5 \mu \mathrm{s} / \mathrm{div})$, current through L2, $i_{L 2}(5 \mathrm{~A} / \mathrm{div}, 5 \mu \mathrm{s} / \mathrm{div})$.

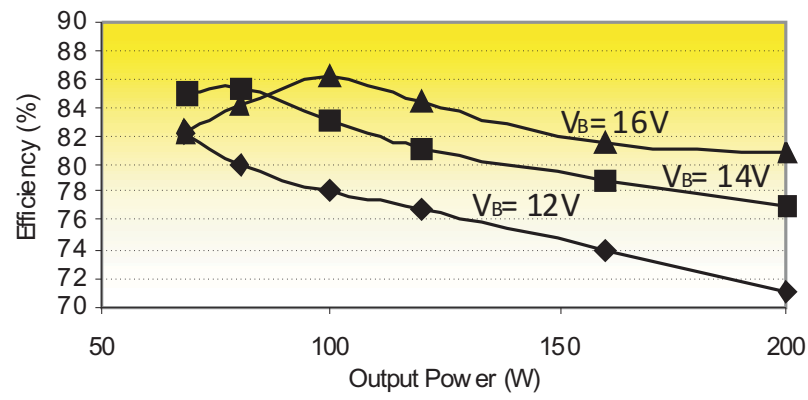

Fig. 15. Efficiency of the converter for $V_{C}=400 \mathrm{~V}$.

voltages, $V_{C}=100 \mathrm{~V}$ and $V_{C}=400 \mathrm{~V}$, with duty cycles lower and higher than $50 \%$, respectively.

Inductors (TF1 and TF2) were designed with toroidal cores in order to reduce the turns. Several MOSFETs have been placed in parallel to implement M5 and M6, in order to reduce conduction power losses. Turns-relations $n_{p}$ and $n_{f}$ were selected in a 1:7 ratio, in order to use M5 and M6 to support voltage stresses lower than $100 \mathrm{~V}$ and the capability to vary the duty cycle appropriately. Synchronous MOSFETS in $\mathrm{D} 1$ to $\mathrm{D} 4$ where used in order to reduce the conduction power losses. Table III shows specifications in semiconductor and magnetic elements.

\section{A. Start-up mode}

Figure 11 shows, from top to down, the gate signal, the drain source voltage for M5 ( $\left.V_{D S M}\right)$, the current through L1 and the current DF1. In this operation mode, the converter works with a duty cycle lower than $50 \%\left(V_{C}=100 \mathrm{~V}\right)$ and the energy is transferred to the output through TR, TF1 and TF2. Figure 12 shows the efficiency of the converter in this operation mode. 


\section{B. Normal mode}

In Figure 13, observe that the output voltage increases from $0 \mathrm{~V}$ to $400 \mathrm{~V}$, and that the currents in both inductors increase without showing excessively high peaks, since the topology can operate correctly with duty cycles lower than $50 \%$. At approximately 2 seconds, the voltage $V_{C}$ waits before the duty cycle continues to increase; this is because of the design of the control system (in that point, the duty cycle is exactly $50 \%$ ). Figure 14 shows the waveforms obtained, voltage $V_{p}$ of the secondary of the transformer $\mathbf{T R}$, current $i_{p}$ of the secondary of the transformer $\mathbf{T R}$, and the current in each one of the inductors of the converter $\left(i_{L 1}, i_{L 2}\right)$. These waveforms correspond to the operation in steady-state of the converter for Normal mode.

Figure 15 shows the total efficiency of the converter working with distinct input voltages in $V_{B}(12 \mathrm{~V}, 14 \mathrm{~V}$ and $16 \mathrm{~V})$. Observe that the best efficiency is achieved with the highest input voltage $V_{B}$. That is due to the fact that the duty cycle in the MOSFETs increases, causing an increase in the rms currents of the inductors $\mathbf{L} \mathbf{1}$ and $\mathbf{L} \mathbf{2}$ and, also, in the primary and the secondary of the main transformer TR. This fact causes that elevated conducted losses are presented in the topology. In order to minimize these conduction losses an optimization of the inductors and the transformer has to be made.

\section{CONCLUSIONS}

An isolated two-inductor boost converter has been proposed and tested. The converter can be used in those cases where the high voltage bus is held by a bank of capacitors. The voltage may range between 0 and $420 \mathrm{~V}$ in steady-state conditions, a characteristic improves the capabilities of most of the proposed converters in the references. The converter provides two methods to start up. In one, it operates as two Flybacks working in parallel and, in the second, it operates as Boost + Flyback. The second method was implemented in the prototype and it operates correctly without problems for duty cycles lower than $50 \%$. A test operation with $100 \mathrm{~V}$ was conducted and it was found that the converter works properly. A $200 \mathrm{~W}$ prototype has been built and tested. The measured waveforms are in good agreement with the expectations. The results obtained from this topology make it a good candidate to be used in applications were a high relation between input and output voltage is necessary.

\section{REFERENCES}

[1] L. Yan and B. Lehman, "Isolated two-inductor boost converter with one magnetic core", in Proc. IEEE Applied Power Electronics Conference and Exposition, vol. 2, pp. 879-875, 2003.

[2] Y. Jang and M. M. Jovanovic, "New two-inductor boost converter with auxiliary transformer", in Proc. IEEE Applied Power Electronics Conference and Exposition, vol. 2, pp. 654-660, 2002.

[3] Y. Jang and M. M. Jovanovic, "New two-inductor boost converter with auxiliary transformer", IEEE Transactions on Power Electronics, vol. 19, pp. 169-175, June 2004.
[4] H. Seung-Hoon R. Chung-Wook and Y. Myung-Joong, "Dual coupled inductor fed isolated boost converter for low input voltage applications", Electronics Letters, vol. 35, pp. 1791-1792, Oct 1999.

[5] W. C. P. de Aragao Filho and I. Barbi, "A comparison between two current-fed push-pull DC-DC convertersanalysis, design and experimentation", in Proc. IEEE International Telecommunications Energy Conference, pp. 313-320, 1996.

[6] I. Elkin G. Ivensky and S. Ben-Yaakov, "An isolated DCDC converter using two zero current switched IGBTs in a symmetrical topology", in Proc. IEEE Power Electronics Specialists Conference, vol. 2, pp. 1218-1225, 1994.

[7] P. J. Wolfs, "A current-sourced dc-dc converter derived via the duality principle from the half-bridge converter", IEEE Transactions on Industrial Electronics, vol. 40, pp. 139-144, Feb 1993.

[8] F. C. Lee L. Zhu, K. Wang and J.-S. Lai, "New startup schemes for isolated full-bridge boost converters", in Applied Power Electronics Conference, vol. 1, pp. 309313, 2000.

[9] F. C. Lee L. Zhu, K. Wang and J.-S. Lai, "New start-up schemes for isolated full-bridge boost converters", IEEE Transactions on Power Electronics, vol. 18, pp. 946-951, July 2003.

\section{BIOGRAPHIES}

Luis A. Flores-Oropeza (M'06) was born in Aguascalientes, Mexico, in 1976. He received the Masters degree in electrical engineering from Instituto Tecnológico de Aguascalientes, Mexico in 1999 and Doctoral degree in electronic engineering from the Universidad Politécnica de Madrid, Spain, in 2005.

$\mathrm{He}$ is currently an Associate Professor at the Universidad Autónoma de Aguascalientes. His current research interests include switching mode power supplies and power factor correction.

Alejandro Román-Loera (M'06) was born in D.F., Mexico in 1976. He received the Masters degree in electronic engineering from Instituto Tecnológico de Aguascalientes in 2002.

He is currently an Associate Professor at the Universidad Autónoma de Aguascalientes.

Jorge E. Macías-Díaz was born in Aguascalientes, Mexico, in 1970. He received a doctoral degree in mathematics from the University of Tulane, New Orleans, in 2001, and second doctoral degree in physics from the University of New Orleans in 2007.

$\mathrm{He}$ is currently a Full Professor at the Universidad Autónoma de Aguascalientes, where he conducts research in pure mathematics and theoretical physics.

Felipe de J. Rizo-Díaz was born in Guadalajara Jal., Mexico in 1964. He received the Masters degree in electronic engineering from Instituto Tecnológico de Estudios Superiores de Occidente (ITESO) in 2000.

$\mathrm{He}$ is currently an Associate Professor at the Universidad Autónoma de Aguascalientes. His current research interests include switching mode power and electronics ballast. 